\title{
MATHEMATICAL LOGIC IN ASCERTAINING THE ACCURACY OF THE TERM “CORRUPTION” AS BASIC INTERFACE OF FRAUD IN FINANCIAL INSTITUTIONS
}

\author{
Nataša Ćetković \\ Sudski veštak za oblast mašinske tehnike, Sremska Kamenica, Srbija
}

OMESTE

JEL Kategorija: D73, G23

\begin{abstract}
Apstrakt
Potreba finansijskih institucija za kontinuiranom borbom sa svim pojavnim oblicima prevara je tema kojom se trenutno $i$ veoma aktivno bave različita udruženja, agencije i forumi, ali je opšti pristup ovoj temi još uvek na teorijsko-edukativnom nivou. Ako uzmemo u obzir nespornu činjenicu da prevara kao pojavni oblik vrste kriminala postoji koliko i finansijske institucije, da su prevare i korupcija u finansijskim institucijama u značajnoj ekspanziji već duži niz godina, te da je za očekivati samo progresivan porast ovih kriminalnih dela u budućem periodu, ovaj rad ima za cilj da analizom retrospektive borbe sa prevarama, ukaže na značaj organizovane borbe i inicira realno ostvarive aktivnosti od strane finansijskih institucija kao lidera tržišne ekonomije, kako bi dejstvovale organizovano na putu ostvarenja optimalnog stepena zaštite od prevara sa koruptivnim prefiksom. Tema ovog stručnog rada je primena Matematičke logike nad prevarama koje su skupovi događaja i povezanih aktivnosti pod nazivom „prevara sa korupcijom”. Prevara je pravna kategorija za čije otkrivanje je moguće formirati određene jezičke izraze i kao takve ih permanentno obrađivati matematičkom logikom. Dobijeni podaci tipa "istina” ili „neistina” trajno bi se pohranjivali na server kompanije. Uparivanjem input iskaza putem matematičke logike stalno bi pratili aktivnosti aktera u finansijskim procesima i generisali output iskaze koji bi odražavali stepen prisustva koruptivnog delovanja.
\end{abstract}

Adresa autora:

Nataša Ćetković

䤵 natasa.cetkovic.ns1@gmail.com
Ključne reči: Logika, matematička logika, prevara, indikacije prevare, interne prevare, eksterne prevare, korupcija, interfejs, input iskazi, output iskazi. 


\begin{abstract}
The need of financial institutions insurance to continuously fight all manifestations is a topic that is currently and quite actively addressed by various associations, agencies and forums. However, a general approach to this topic is still at a theoretical and educational level. If we take into consideration the indisputable fact that fraud as manifestation of a type of crime has existed as long as financial institutions, that the number of frauds \& corruption in finacial instituions has been considerably increasing for a long stretch of years, and that we can only expect a progressive increase in the number of these criminal acts in the period to come, this paper aims to analyze the fight against frauds in retrospect and thereby point out to the significance of organized fight against frauds and initiate realistically feasible activities of financial institutions as a leader of the market economy so as to enable to act in an organized manner on the road of achieving an optimum level of protection against fraud with corruption prefix. The theme of this expert work is aqpplication of Mathematical logic to a specific type of fraud called "fraud with corruption". Fraud as a legal category can be detected by establishing certain linguistic terms and processing them as such using mathematical logic. The resulting "true" or "untrue" types of data would be permanently stored on the company server. By pairing input statements using mathematical logic we can monitor the activities of players in financial processes, and generate output statements that would reflect the degree of presence of corrupt activities.
\end{abstract}

Keywords: Logic, mathematical logic, fraud, fraud indicators, internal fraud, external fraud, corruption, interface, input statements, output statements.

\section{UVOD}

Prevara nikada nije samo jedan događaj, već niz uzajamno povezanih aktivnosti. Akteri istih su različiti, kako po svojoj osposobljenosti da vrše prevare tako i po ciljevima, u smislu očekivanih novčanih iznosa, koje su spremni da protivpravno pribave sebi ili trećim licima, kao i spremnosti da ove aktivnosti ciklično ponavljaju u istoj ili sličnoj finansijskoj instituciji. (NBS, 2007)

Logika, kao veština i metod pravilnog razmišljanja koristi se u najrazličitijim oblastima

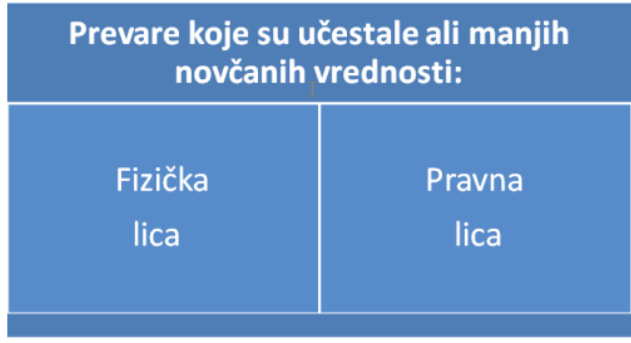

Slika 1: Oportunističke prevare

Ako ovakva lica ne budu pravovremeno razotkrivena, praksa otkrivanja prevara je pokazala i dokazala da su počinici istih dela sve spremniji da ove aktivnosti usavršavaju, sprovode sve učestalije, a skoro matematičkom progresijom permanentno se povećavaju i novčani iznosi nauke. Kao takva, primenjuje se i kod niza aktivnosti na otkrivanju kako internih tako i eksternih prevara, koje ćemo kao pojavne oblike dodatno pojasniti u nastavku rada.

Međutim, kod eksternih prevara, koje mogu biti oportunističke i profesionalne, uvek postoji potencijalna opasnost da nije uočena međusobna povezanost delovanja interno zaposlenih lica, ispoljena kroz njihovo insajdersko-koruptivno delovanje radi sticanja lične materijalne koristi.

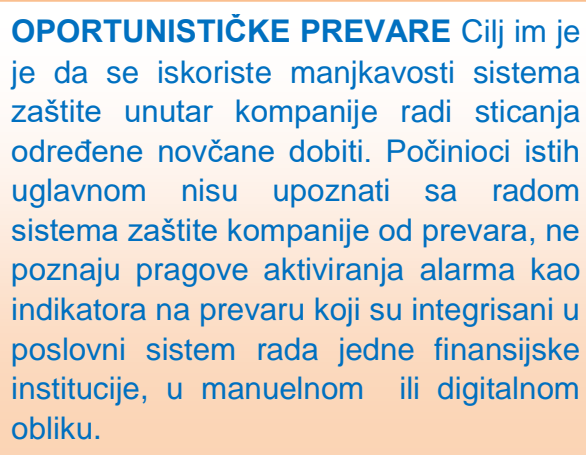
zaštite unutar kompanije radi sticanja određene novčane dobiti. Počinioci istih uglavnom nisu upoznati sa radom sistema zaštite kompanije od prevara, ne poznaju pragove aktiviranja alarma kao indikatora na prevaru koji su integrisani u poslovni sistem rada jedne finansijske institucije, u manuelnom ili digitalnom obliku.

protivpravno otuđenog novca, sa tendencijom da vremenom, interno zaposlena lica postanu idejni tvorci i glavni organizatori različitih oblika eksternih prevara, za koje pružaju internu logističku podršku. 


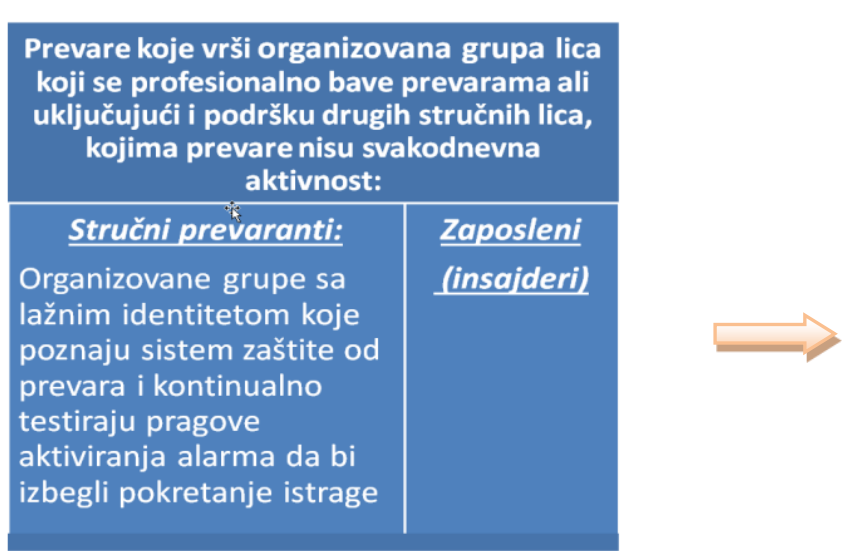

Slika 2: Profesionalne prevare - organizovani kriminal

Prvi skup pravila deduktivnog zaključivanja obradio je još grčki filozof Aristotel (384-322 p.n.e) u svom delu Organon (Aristotle, Cooke, Tredennick, \& Forster, 1938), što u prevodu znači oruđe.

Zakone logike i pravila rasuđivanja je engleski matematičar i filozof Džordž Bul (George Boole;1815. -1864.) uveo u matematiku. Tako je stvorena matematička logika ili simbolična logika i algebra logike nazvana Bulova algebra.
PROFESIONALNE PREVARE Cilj je da se pokušaju iskoristiti manjakavosti sistema zaštite unutar kompanije radi sticanja velike novčane dobiti. Počinioci istih su upoznati sa radom sistema zaštite kompanije od prevara, uglavnom od strane interno zaposlenih lica $u$ kompaniji, koja su spremna da insajdersko-koruptivnim delovanjem, omoguće sebi i drugima sticanje pritivpravne koristi. Interno zaposlena lica raspolažu potrebnim informacijama ili su u prilici da sprovedu određene aktivnosti kao bazičnu osnovu za uspeh delovanja kriminalno organizovane grupe.

Za otkrivanje bazičnog interfejsa koji nazivamo „korupcijom” moguće je kreirati softverski alat - ORUĐE kojim će se upravljati upitima nad kreiranim iskazima za svaku poslovnu funkciju kompanije. Tako bi se permanentno sprovodila TRIJAŽA kroz sve faze procesa rada kompanije i obezbeđivala kontinuirana selekcija informacija.
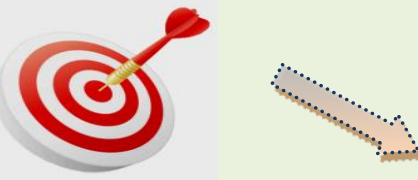

\section{Trijaža aktera procesa ali kako?}

Cilj je da se brojni podaci "benignog" sadržaja sistematski beleže, bez dodatnih ljudskih resursa, automatski obrađuju i permanentno dopunjavaju, sve do okončanja i zadnje faze procesa nad određenim skupom podataka. Kao rezultat ovih aktivnosti generišu se output iskazi u obliku postavke:

\section{Postoji li osnovana sumnja u korupciju? ili \\ 2. Može se dokazati koruptivno delovanje? (ali u mnogo manjem procentu mogućih slučajeva)}

Permanentan nadzor nad aktivnostima internih učesnika koji obavljaju tipske vrste poslova visokog stepena izloženosti korupciji, gde i samo saznanje da "sistem odbrane" egzistira u kompaniji, dejstvuje kao efikasna preventivna zaštita odvraćanja potencijanih izvršilaca od svojih namera, obzirom da su šanse da budu otkriveni višestruko uvećane.

S obzirom na to da je poznato da računari imaju mogućnost da svaku informaciju, odnosno podatak, memorišu i obrađuju u obliku niza bitova, moguće je obrađivati nenumeričke ili bolje reći tekstualne podatke. Jedna binarna cifra (bit) 0 ili 1 predstavlja minimalnu količinu infomacija, odnosno najmanji podatak koji se može obraditi na računaru.

Bit može da reprezentuje istinu (true) ili neistinu (false). 
Output iskazi koji nastaju kao rezultat obrade input iskaza uglavnom ne daju kompletne informacije koje se mogu smatrati dokazom za sud (slično kao kod analize iskaza lica putem poligrafa), ali je izvesno da omogućavaju internim službama kontrole, revizije poslovanja i konsaltinga, da se fokusiraju na ukazane sporne detalje, što bi sasvim izvesno povećalo i procenat otkrivenih i dokazanih prevara.

\section{PRIMENA MATEMATIČKE LOGIKE}

\subsection{Pojam prevare}

Pod prevarom se podrazumeva činjenje ili nečinjenje sa namerom sticanja nepoštene ili protivzakonite koristi za učesnika u prevari ili za treće lice. (v. sl. 1 i 2 )

Za postojanje prevare neohodan je: lažni prikaz ili prikrivanje neke činjenice ili okolnosti; znanje svest o lažnom prikazu i namera da se učini prevara i na taj način stekne neka korist koja učiniocu ili trećem licu ne pripada, a sa druge strane savesnost prevarene strane, odnosno okolnost da se ona opravdano uzdaje $u$ istinitost takvog prikaza.

Zbog postojanja namere, prevara se i razlikuje od greške, koja ima karakter nenamernog postupka ili propusta.

\subsection{Indikacija na prevaru}

Pod indikacijom prevare podrazumeva se svaka materijalno značajna radnja koja ukazuje na osnovanu sumnju postojanja elemenata krivičnog dela, privrednog prestupa

ili prekršaja, povrede radne obaveze ili prikrivanje materijalnih ili finansijskih činjenica.

\subsection{Vrste aktera prevare po mestu delovanja}

1. Interne prevare, gde se pod internim prevarama podrazumevaju sve prevare u koje su uključena lica interno zaposlena u konkretnoj finansijskoj instituciji. Za sve aktere iz ove grupe uvodimo iskaznu skraćenicu (lu)aktivnosti internih učesnika.

2. Eksterne prevare, gde se pod eksternim prevarama podrazumevaju sve prevare u koje su uključena lica iz eksternog okruženja, ali interesno povezana sa konkretnom finansijskom institucijom, direktno ili indirektno. Za sve aktere iz ove grupe uvodim iskaznu skraćenicu (Eksu)-aktivnosti eksternih učesnika.

\subsection{Iskazi i njihova primena}

Za nastavak dalje analize neophodno je prema (Doroslovački, 2014, str. 3-77), konstatovati sledeće:

- Svaka rečenica se ne smatra iskazom

- Da bi jedna rečenica bila iskaz u smislu matematičke logike, ona mora biti tako koncipirana da može biti samo tačna ili netačna.

Ako matematičku logiku nameravamo koristiti na način kako sam prethodno pojasnila u uvodnom delu rada, rečenice - iskazi moraju biti tako koncipirane da imaju samo jednu od istinitosnih vrednosti: istinit (tačan-true) i neistinit (netačanfalse).

U tom cilju, kao i u matematici, uvedimo sledeće oznake:

$$
\begin{aligned}
& T \text { - za tačno (čita se te) } \mathrm{i} \\
& \perp-\text { za netačno (čita se ne-te) }
\end{aligned}
$$

Istinitost jednog iskaza koji uvek predstavlja jednu rečenicu kojom se opisuje rezultat u odnosu na:

1. jedan događaj,

2. jednu aktivnost,

3. jednog aktera,

4. u istom, jasno definisanom i standardizovanom procesu,

što ćemo radi boljeg shvatanja označiti kao i u matematici, grčkim slovom $\tau$ (tau).

\subsection{Primena osnovnih logičkih operacija i oznaka}

Prema konstataciji (Doroslovački, 2014), zaista se može prihvatiti da su matematička logika, iskazna algebra, u stvari ovozemaljska ljudska logika. Nema logičkog pristupa prevarama bez ukrštanja znanja različitih profila profesionalne stručnosti $i$ stečenog iskustva.

Ako menadžment prepozna kao strateški cilj kompanije tzv. "nultu toleranciju" kao problem 
prevara koje prerastaju u viši koruptivni oblik, moguće je osmisliti logičke input iskaze za softver koji će omogućiti izvršiocima koji rade na različitim poslovima, različitih profila i stepena stručnosti, da tokom obavljanja svakodnevnih poslovnih aktivnosti, bez neophodnog znanja $i$ iskustva na polju otkrivanja prevara i korupcije, prostim čekiranjem odgovora na definisane input iskaze, pripremaju bazu podataka koji se potom, prema unapred definisanim formulama-pravilima, ukrštaju tj. uparuju primenom adekvatnih i poznatih logičkih operacija.

Proces ukrštanja-uparivanja odgovora na iskaze iz skupova (lu1,2,3,...) i (Eksu1,2,3,...) koji su realno input-iskazi, obrađuje se putem softverske podrške, kao modelom modernog oruđa ljudske logike.

Poznato je da su osnovne logičke operacije (i oznake logičkih operatora):

- konjukcija (i), konjukcija je tačna samo ako su oba iskaza tačna,

- disjunkcija (ili), disjunkcija je netačna samo ako su oba iskaza netačna,
- implikacija (ako-onda), implikacija je netačna jedino u slučaju kada je jedan iskaz tačan a drugi netačan,

- i ekvivalencija (ako i samo ako), ekvivalencija je tačna samo ako oba iskaza imaju istu istinitu vrednost,

- vrste osnovnih logičkih veznika binarnog tipa, dok je samo jedan, tzv. unarni veznik (log. oper.) koji od jednog iskaza lu ili Eksu pravi jedan novi iskaz, složeniji,

- negacija, negacija iskaza znači da je iskaz "ne lu" ili "ne Eksu" tačan samo ako iskaz lu ili Eksu nije tačan.

Tabela 1: Oznake logičkih operacija koje će se koristiti u formiranju output iskaza

\begin{tabular}{|cc|}
\hline logički veznik & oznaka \\
\hline nije & $\neg$ \\
i & $\wedge$ \\
ili & $\vee$ \\
ako ... onda ... & $\Rightarrow$ \\
ako i samo ako & $\Leftrightarrow$ \\
\hline
\end{tabular}

Tabela 2: Istinitosna vrednost logičkih operacija

\begin{tabular}{|c|c|c|c|c|c|c|}
\hline $\begin{array}{c}\tau \\
\text { (lu) }\end{array}$ & $\begin{array}{c}\tau \\
\text { (Eksu) }\end{array}$ & $\begin{array}{c}\tau \\
(\mathrm{lu} \wedge \mathrm{Eksu})\end{array}$ & $\begin{array}{c}\tau \\
(\text { lu } \vee \text { Eksu) }\end{array}$ & $\begin{aligned} & \tau \\
&(\mathrm{lu} \Rightarrow \mathrm{Eksu})\end{aligned}$ & $(\mathrm{lu} \Leftrightarrow \mathrm{Eksu})$ & $\begin{array}{c}\tau(\neg \mathrm{lu}), \\
/ \tau(\neg \text { Eksu })\end{array}$ \\
\hline $\mathrm{T}$ & $\mathrm{T}$ & $\mathrm{T}$ & $\mathrm{T}$ & $\mathrm{T}$ & $\mathrm{T}$ & $\perp \quad / \perp$ \\
\hline $\mathrm{T}$ & $\perp$ & $\perp$ & $\mathrm{T}$ & $\perp$ & $\perp$ & $\perp \quad / \mathrm{T} /$ \\
\hline$\perp$ & $\mathrm{T}$ & $\perp$ & $\mathrm{T}$ & $\mathrm{T}$ & $\perp$ & $\mathrm{T} \quad / \perp /$ \\
\hline$\perp$ & $\perp$ & $\perp$ & $\perp$ & $\mathrm{T}$ & $\mathrm{T}$ & $\mathrm{T} \quad / \mathrm{T} /$ \\
\hline
\end{tabular}

Tabela 3: Prioriteti logičkih operatora

\begin{tabular}{|l|c|}
\hline Logički operatori & Prioritet \\
\hline Negacija & 1 (najviši stepen) \\
\hline Konjukcija i disjunkcija & 2 \\
\hline Implikacija i ekvivalencija & 3 \\
\hline
\end{tabular}




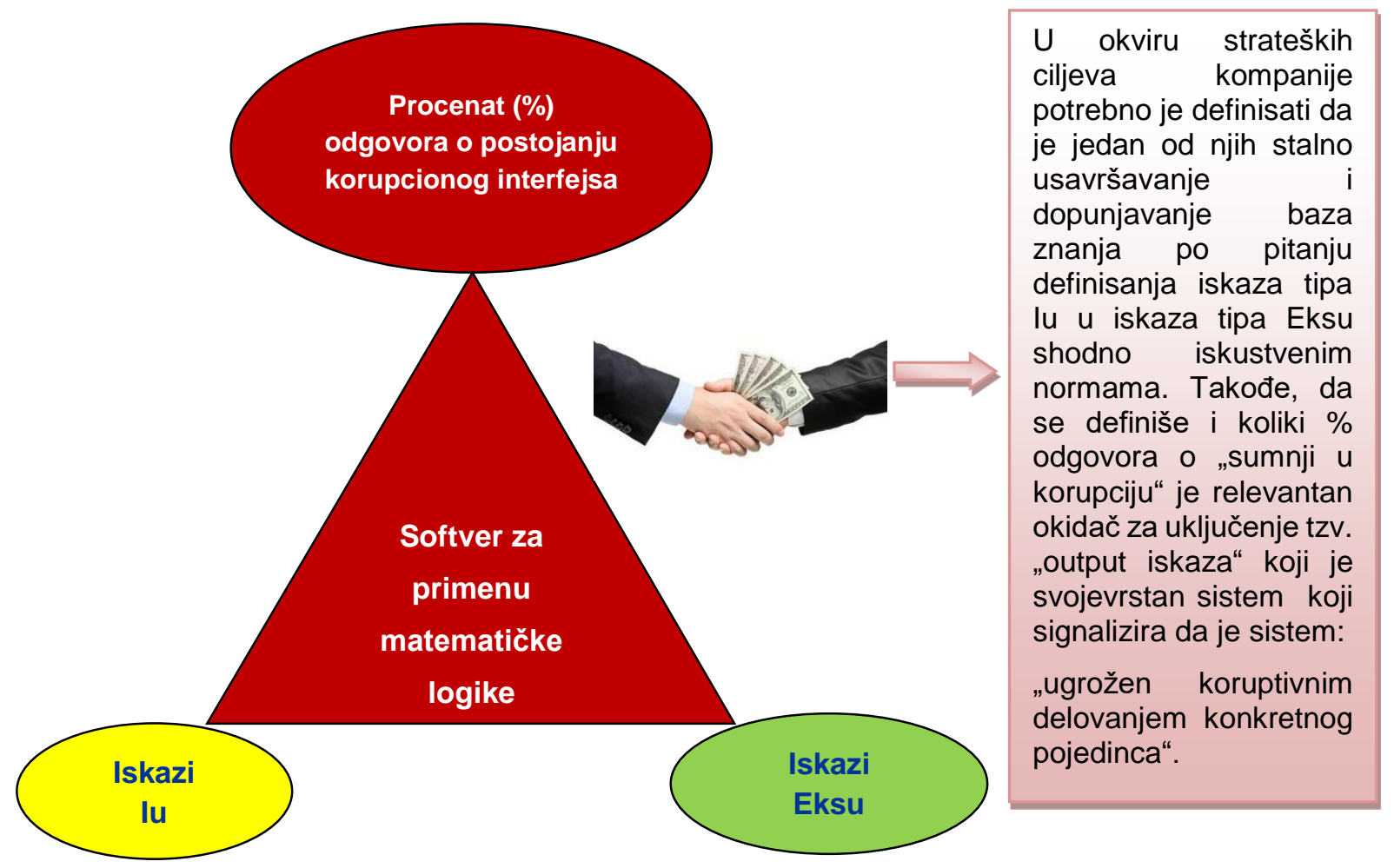

Slika 3: Dijagramski prikaz softverske obrade podataka matematičkom logikom

Adekvatnim kombinovanjem iskaznih izraza i logičkih operatora dobijamo složene izraze koji će nam jednostavno pružati odgovore istinosnih vrednosti ovih izraza. Da bi tako nešto zaista mogli primeniti u svakodnevnom životu, veoma je važno kako unificirano, za određene aktivnosti odnosno procese, osmisliti izraze (lu) i (Eksu), pa nad njima primenjivati poznati matematički prioritet logičkih operacija, kako bi izneti zaključak bio upotrebljiv u konačnom obliku.

Pod konačnim oblikom podrazumevamo:

- postoji sumnja u koruptivno delovanje pojedinca ili grupe - pojačati nadzor,
- postoje dokazi u koruptivno delovanje pojedinca ili grupe - pokrenuti krivični postupak

\section{INPUT I OUTPUT ISKAZI}

Unos ulaznih input parametara vrše interno zaposlena lica u različitim poslovnim funcijama kompanije, gde tokom sprovođenja redovnih aktivnosti koje se kao takve unose u informatički system (Doroslovački, 2014), ujedno odgovaraju na unapred definisane iskaze po principu "istina" ili "neistina".

Prema navodima iz (Ćetković \& Ćetković, 2014), i ovaj sistem mora da funkcioniše po principu "LEVKA"

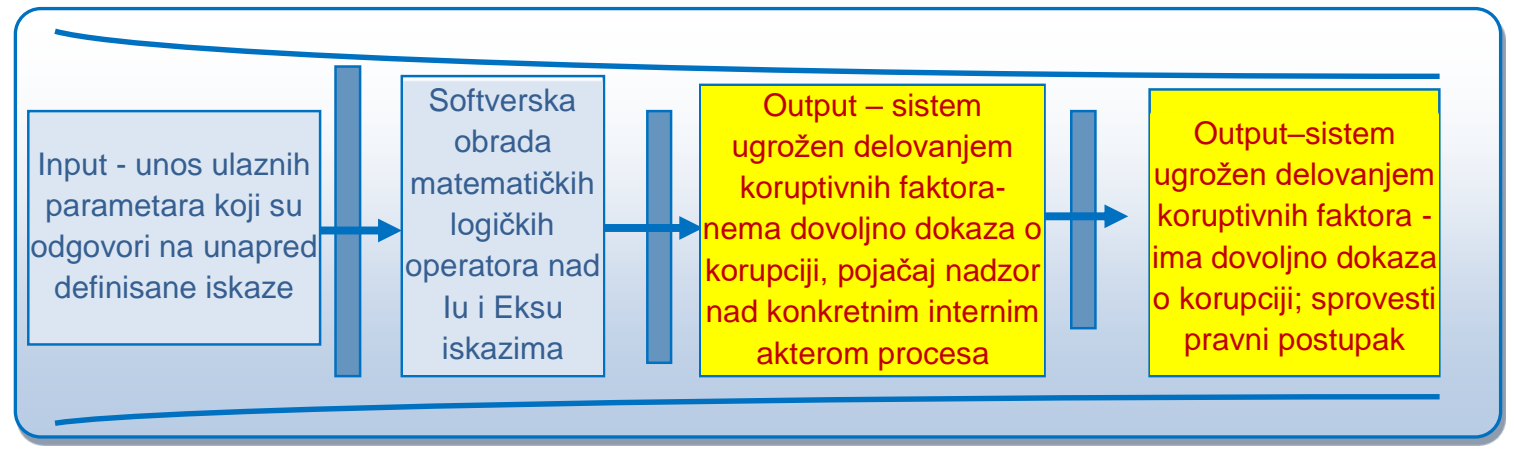

Slika 4: Radni tok input i output iskaza - ponovo princip "LEVKA" 
Preporuka da bi se ispunio uslov iz slike 4 je:

- Minimalno preporučen broj iskaznih rečenica koje će se obrađivati za jednu poslovnu oblast kompanije je 5 .

- Minimalno preporučen broj iskaznih vrednosti koje će se obrađivati putem matematičke analize na kraju definisanja input iskaza je 10,

- Preporučeni procenat (\%) vrednosti koje bi trebalo da postanu okidač alarma "sumnje u postojanje korupcionog interfejsa" jeste ne manje od $70 \%$ mogućih rezultata.

\section{ZAKLJUČAK}

Svaka finansijska institucija mora samostalno da sagleda svoje poslovanje i potencijalne opasnosti koje kao rizik preuzimaju pojedini akteri određene poslovne oblasti, te da permanentno radi na formiranju iskaza koje će potom usavršavati, a adekvatno opredeljenim logičkim operatorima povezivati $u$ prethodno definisanu funkcionalnu celinu.
Uključenje, odnosno aktiviranje "informatičkog alarma" ukazuje na postojanje koruptivnog delovanja pojedinca ili povezane grupe lica unutar kompanije što pretpostavlja izvesnu i očekivanu posledicu primene input $\mathrm{i}$ output iskaza $u$ poslovanju jedne kompanije. Uzročno implementira specijalan pristup visokog menadžmenta kompanije svim povezanim poslovnim procesima u kojim i oni učestvuju, a u dužem vremenskom periodu.

Potom slede sve ostale aktivnosti koje su definisane u Kriminologiji koja se kao sintetička i samostalna nauka bavi izučavanjem kriminaliteta kao društvene pojave, odnosno oblika ponašanja koji su inkriminisani i sankcionisani pozitivnim pravom u datom društvu.

U mnogo dosadašnjih stručnih radova, koji su takođe izučavali i obrađivali ovu tematsku oblast, izrečena je važna činjenica koja se ističe kao nepobitan postulat: gotovo ne postoje eksterne prevare bez unutrašnje - insajderske podrške.

\section{CITIRANI RADOVI}

Aristotle, Cooke, H. P., Tredennick, H., \& Forster, E. S. (1938). The Organon. London, GB: William Heinemann Ltd. Retrieved from http://www.constitution.org/ari/aristotle-organon+physics.pdf

Ćetković, N., \& Ćetković, P. (2014). Dijalektički pristup primene indikatora prevara implementiranih kroz informatički sistem podrške likvidaciji šteta. Zbornik radova sa Savetovanja Zlatibor 2014 (str. 1-8). Čigota - Zlatibor, Srbija: Agencije „Expert“ - Beograd.

Doroslovački, R. (2014). Principi algebre opšte, diskretne i linearne (3 izd.). Novi Sad: FTN Novi Sad.

NBS. (2007). Smernica broj 6. Službeni glasnik RS, 1-7.

Shannon, C. (1948, July, October). A Mathematical Theory of Communication. The Bell System Technical Journal, 27, 379-423, 623-656. Retrieved from http://worrydream.com/refs/Shannon\%20-

\%20A\%20Mathematical\%20Theory\%20of\%20Communication.pdf

Datum prve prijave:

Datum prijema korigovanog članka:

Datum prihvatanja članka:
24.11.2014.

08.09.2015.

18.09.2015.

\section{Kako citirati ovaj rad? / How to cite this article?}

\section{Style - APA Sixth Edition:}

Ćetković, N. (2016, januar 15). Matematička logika otkrivanja tačnosti izraza "korupcija" kao bazičnog interfejsa prevara u finansijskim institucijama. (Z. Čekerevac, Ur.) FBIM Transactions, 4(1), 2835. doi:10.12709/fbim.04.04.01.03 
Style - Chicago Sixteenth Edition:

Ćetković, Nataša. 2016. „Matematička logika otkrivanja tačnosti izraza "korupcija" kao bazičnog interfejsa prevara u finansijskim institucijama." Urednik Zoran Čekerevac. FBIM Transactions (MESTE) 4 (1): 28-35. doi:10.12709/fbim.04.04.01.03.

Style - GOST Name Sort:

Ćetković Nataša Matematička logika otkrivanja tačnosti izraza "korupcija" kao bazičnog interfejsa prevara u finansijskim institucijama [Časopis] // FBIM Transactions / ur. Čekerevac Zoran. - Beograd : MESTE, 15 januar 2016. - 1 : T. 4. - str. 28-35.

Style - Harvard Anglia:

Ćetković, N., 2016. Matematička logika otkrivanja tačnosti izraza "korupcija" kao bazičnog interfejsa prevara u finansijskim institucijama. FBIM Transactions, 15 januar, 4(1), pp. 28-35.

Style - ISO 690 Numerical Reference:

Matematička logika otkrivanja tačnosti izraza "korupcija" kao bazičnog interfejsa prevara u finansijskim institucijama. Ćetković, Nataša. [ur.] Zoran Čekerevac. 1, Beograd : MESTE, 15 januar 2016, FBIM Transactions, T. 4, str. 28-35. 